\title{
Hereditary Factors in Esophageal Adenocarcinoma
}

\author{
Anna M.J. van Nistelrooija, b Winand N.M. Dinjens ${ }^{b} \quad$ Anja Wagner ${ }^{c}$ \\ Manon C.W. Spaander ${ }^{d} \quad$ J. Jan B. van Lanschot ${ }^{a}$ Bas P.L. Wijnhoven ${ }^{a}$ \\ Departments of a Surgery, ${ }^{b}$ Pathology, ${ }^{c}$ Clinical Genetics and ${ }^{d}$ Gastroenterology, \\ Erasmus MC, University Medical Center, Rotterdam, The Netherlands
}

\section{Key Words}

Hereditary factors · Esophageal adenocarcinoma · Barrett's esophagus

\begin{abstract}
Background: The vast majority of Barrett's esophagus (BE) and esophageal adenocarcinoma (EAC) cases are sporadic and caused by somatic mutations. However, over the last decades several families have been identified with clustering of EAC. Here, we review data from the published literature in order to address the current knowledge on familial EAC.

Summary: Although familial EAC comprises a relatively small group of patients, it is a clinically relevant category due to the poor prognosis of this type of cancer. Efforts should be made to identify specific genetic risk factors for familial EAC to enable identification of relatives at risk, since endoscopic surveillance can diagnose preneoplastic or early neoplastic lesions leading to early treatment, with improved outcome.

Key Message: Although familial EAC comprises a relatively small group of patients, this is a clinically relevant category due to the poor prognosis. Efforts should be made to identify specific genetic risk factors for familial EAC in order to facilitate the identification of other family members with a predisposition for this type of cancer.

Practical Implications: Approximately $7 \%$ of BE and EAC cases are considered familial. Age at diagnosis is generally lower for patients with familial EAC as compared to sporadic cases, while other known risk factors for EAC, such as male gender and Caucasian ethnicity, do not differ between the two groups. In several described families with clustering of EAC the pattern of inheritance seems to be consistent with a rare autosomal dominant genetic trait. However, some association has been found with (attenuated) familial adenomatous polyposis, mismatch repair deficiency and recently with the genes MSR1, ASCC1 and CTHRC1. Nevertheless, no specific genetic predisposition has yet been identified.




\section{Introduction}

During the last decades there has been a dramatic increase in the incidence of esophageal adenocarcinoma (EAC) in Western countries [1-3]. Despite improvements in multimodality therapy, the prognosis of patients with EAC remains poor [4]. Barrett's esophagus (BE) is the predominant risk factor for EAC in addition to age, male gender and Caucasian ethnicity [5]. $\mathrm{BE}$ is a premalignant condition in which the normal squamous epithelial lining in the lower esophagus is replaced by columnar intestinal cells [6]. BE is considered a long-term complication of severe chronic gastroesophageal reflux disease (GERD). The susceptibility for GERD may in turn be influenced by factors such as obesity, alcohol consumption and nicotine abuse [7].

The vast majority of BE and EAC cases are sporadic and caused by somatic mutations [8], i.e. mutations that may occur in any cell of the body except for germ cells. However, over the last decades several families have been identified with clustering of EAC [9-14]. This observation suggests that one or more inherited factors might play a role in the initiation of EAC in these families. Familial clustering of cancer is important thanks to the success of implementing genetic testing and screening methods for cancer syndromes [15-17]. However, for cancers that are not covered in familial risk management guidelines, such as EAC, awareness of the true familial risk is needed to provide rational advice [17]. In terms of clinical genetics, for a true familial risk, the number of affected family members needs to be higher than is to be expected by chance alone [18].

The purpose of the present study was to review the literature on the occurrence and characteristics of familial EAC. Previous studies introduced and persevered the definition familial BE, i.e. two or more first- or second-degree family members diagnosed with BE, EAC or gastroesophageal junction adenocarcinoma (GEJAC) [19]. These studies considered familial BE and familial EAC to be part of the same genetic trait, because EAC appears to arise from $\mathrm{BE}$ and both conditions share the same epidemiologic risk factors. We hypothesize that familial EAC can be distinct from most familial BE. Since BE is much more prevalent among the common population, familial BE does not necessarily have to be the underlying condition of familial EAC. If two or more first-degree family members are diagnosed with EAC, it is unlikely that this can be explained by chance alone, based on the absolute risk of $0.12-0.5 \%$ for malignant transition of BE into EAC [20,21]. Therefore, familial EAC might be the result of accelerated malignant progression from familial BE, or familial EAC might arise without familial BE as the premalignant condition. In both scenarios involvement of specific germline mutations driving familial EAC can be envisaged.

\section{Prevalence of Familial EAC}

In the literature familial EAC has been grouped with familial BE and has been termed familial BE, which is defined as two or more family members diagnosed with BE, EAC or GEJAC [19]. Two studies estimated the prevalence of familial BE by reporting the proportion of patients diagnosed with BE, EAC or GEJAC that had at least one other family member diagnosed with BE, EAC or GEJAC. Chak et al. [22] reported that about 7\% fulfill the criteria of familial BE, which is in line with the $6 \%$ reported by Ash et al. [23]. Including GEJAC in familial $\mathrm{BE}$ can be criticized, since a tumor present on the gastroesophageal junction can originate either from the esophagus or the gastric cardia. In the last instance the tumor probably does not arise from BE. 


\section{Risk of GERD, BE and EAC for Familial EAC}

$\mathrm{BE}$ is generally accepted as the premalignant lesion for EAC. BE is a complication of chronic GERD. The prevalence of BE in the common population is estimated at $2 \%$ [24], while the prevalence of BE among patients with GERD is approximately $10 \%$ [25]. The annual risk of developing EAC from BE is estimated to be between 0.12 and $0.5 \%$ [20, 21]. Two casecontrol studies about the prevalence of GERD among relatives of BE patients suggested a familial predisposition for GERD in these families [26, 27]. Among 27 and 47 relatives of patients diagnosed with $\mathrm{BE}$ or EAC, the prevalence of BE was reported to be $18 \%(n=5)$ and $28 \%(n=13)$, respectively $[28,29]$. More importantly, the prevalence of EAC described among 20 families with a strong familial expression of GERD, BE and EAC was estimated at 31\% [12]. This finding suggests a true familial risk of EAC in these families. In contrast, a Swedish population-based, nationwide case-control study did not find an association between a positive history of esophageal cancer among first-degree relatives and the risk of EAC [30]. In addition, an Italian case-control study revealed no difference in the prevalence of cancer in general between patients diagnosed with $\mathrm{BE}$ and patients with reflux esophagitis plus healthy controls. However, relatives of patients diagnosed with esophageal or gastric cancer had an increased risk of BE, particularly if the affected relative was younger than 50 years at the time of diagnosis [31]. It should be noted that the prevalence of familial BE is relatively low, hence in a randomly taken cohort of patients with BE only a few patients will be part of family with clustering of BE and/or EAC. Although the previously mentioned studies are based on relatively small samples sizes, the prevalence of EAC in these families with clustering of EAC appears to be distinctly higher than in the common population, and this also accounts for the prevalence of $\mathrm{BE}$.

\section{Risk Factors and Patient Characteristics}

Known risk factors for the malignant transition of BE into EAC are increasing age, male gender and Caucasian ethnicity [7]. No differences in gender, ethnicity and in addition in nicotine abuse and alcohol consumption were reported between patients with familial BE and/or EAC and sporadic cases [22, 23, 28, 32]. Contradictory results were observed regarding the prevalence of obesity, with some studies reporting no difference in prevalence $[28,32]$, while others reported a lower body mass index for patients with familial BE and/or EAC compared to sporadic cases [22,33].

Several studies reported a lower age at diagnosis for patients with familial BE and/or EAC compared with sporadic cases $[9,13,23,33,34]$. Other studies could not confirm these observations $[22,28,32]$. In a study on 20 families with a strong familial expression of GERD, BE and EAC, the age at diagnosis of EAC appeared to be 5-10 years younger when compared to sporadic cases [12]. This finding is consistent with the concept of the presence of a germline mutation, which generally results in a lower age at disease onset when compared with sporadic cases. This concept is based on the 'Knudson's two hit hypothesis' for the complete (bi-allelic) inactivation of tumor suppressor genes, i.e. individuals born with already one inactivating germline mutation are likely to develop the second somatic inactivating hit earlier in life than individuals without an inherited predisposition, who have to develop both somatic hits during life in the same cell before tumorigenesis occurs. The second hit may be influenced by environmental and/or by other genetic factors [35]. 
van Nistelrooij et al.: Hereditary Factors in Esophageal Adenocarcinoma

\section{Pattern of Inheritance}

Since 1978 there have been several case reports on families with clustering of BE and EAC [9-14, 34]. All studies suggest a pattern of inheritance consistent with an autosomal dominant genetic trait [9-13], which likely reflects genetic predisposition to the disease. Nevertheless, it can be anticipated that familial EAC can also be caused by common environmental exposures in family members or by a combination of both. However, the segregation analysis (i.e. an analysis to determine whether a certain gene is involved in the distribution of a phenotypic trait) of Sun et al. [36] provided the first epidemiologic evidence in support of a genetic etiology for familial BE, EAC or GEJAC. The pattern of inheritance was found to be consistent with a rare autosomal dominant genetic trait.

\section{Genetic Alterations and Molecular Markers}

Hereditary tumors are generally caused by the presence of germline mutations, which are present in the reproductive cells of one or both of the parents of the affected offspring. Germline mutations are therefore present in all the cells of the affected offspring and can be transmitted from one generation to the next. Colorectal cancer has well-defined familial syndromes due to specific gene mutations. For example, patients with Lynch syndrome have germline mutations in mismatch repair (MMR) genes, and attenuated familial adenomatous polyposis, familial adenomatous polyposis (FAP) and Gardner's syndromes are all caused by germline mutations in the adenomatous polyposis coli (APC) gene [37].

Esophageal lesions are rarely described in these hereditary colorectal cancer syndromes. However, several studies reported the occurrence of BE and/or EAC in patients with (attenuated) FAP or Gardner's syndrome, which are both caused by mutations in the APC gene. Gupta et al. [38] described a family with a father who tested positive for exon 4 deletion in $A P C$. All three of his sons were diagnosed with attenuated familial adenomatous polyposis based on the presence of multiple polyps $(<100)$ throughout the entire colon. The middle son (41 years old) was additionally diagnosed with EAC on the background of BE. A biopsy of the father revealed BE with low-grade dysplasia. In the youngest son BE was also confirmed in histopathological biopsies. The oldest son had endoscopic findings compatible with esophagitis without metaplastic changes. Although the simultaneous occurrence of these two potentially inherited disorders in a single family may be due to chance alone, it is also possible that the disorders are linked. This suggests that deletions of the APC gene could play a role in the pathogenesis of familial BE and subsequently familial EAC. In another study with 36 FAP patients, 6 patients were additionally diagnosed with BE (16.7\%); interestingly, the average age at diagnosis of $\mathrm{BE}$ was 20 years younger than that in the non-FAP patients with $\mathrm{BE}$ [39]. In (attenuated) FAP, APC gene mutations lead to increased nuclear $\beta$-catenin levels and activation of the Wnt pathway. In EAC, although through a different mechanism of Wnt activation, nuclear $\beta$-catenin is also frequently increased [40]. It can be anticipated that the mutation in APC in patients with (attenuated) FAP might increase the chance of developing EAC.

EAC has not been associated with Lynch syndrome. However, 3-5\% of EAC appears to have $M M R$ deficiency [41]. It is unknown, however, whether these tumors arise as part of Lynch syndrome or whether they are due to somatic MMR gene mutations.

Orloff et al. [42] sought to identify genes associated with BE and EAC predisposition. Germline mutations in three candidate genes were identified in approximately $11 \%$ of patients diagnosed with $\mathrm{BE}$ and $\mathrm{EAC}$, the most commonly affected gene being macrophage scavenger receptor 1 (MSR1) [7\%], followed by activating signal cointegrator 1 
complex subunit 1 (ASCC1) and collagen triple helix repeat containing 1(CTHRC1). However, further studies are needed to determine the role of these genes in the development of familial EAC.

\section{Conclusion}

Clustering of EAC in a family is rare but may be caused by an autosomal dominant genetic trait. In view of the poor prognosis of EAC, efforts should be made to identify a genetic predisposition for EAC in these families. Finding a genetic predisposition in familial EAC would facilitate identifying non-affected family members with the predisposition for this type of cancer. Endoscopic surveillance of relatives with the predisposition may lead to the detection of preneoplastic or early neoplastic stages of EAC. Since patients diagnosed with earlier stages of EAC have a better chance for definite cure, this strategy could probably improve outcome [4].

\section{Acknowledgement}

We would like to thank Wirchor Bramer, biomedical information specialist, Medical Library, for coordinating the literature search.

\section{Disclosure Statement}

The authors disclose no conflicts of interest.

\section{References}

$>1$ Bosetti C, Levi F, Ferlay J, Garavello W, Lucchini F, Bertuccio P, et al: Trends in oesophageal cancer incidence and mortality in Europe. Int J Cancer 2008;122:1118-1129.

$\longrightarrow 2$ Brown LM, Devesa SS, Chow WH: Incidence of adenocarcinoma of the esophagus among white Americans by sex, stage, and age. J Natl Cancer Inst 2008;100:1184-1187.

-3 Dikken JL, Lemmens VE, Wouters MW, Wijnhoven BP, Siersema PD, Nieuwenhuijzen GA, et al: Increased incidence and survival for oesophageal cancer but not for gastric cardia cancer in the Netherlands. Eur J Cancer 2012;48:1624-1632.

4 van Hagen P, Hulshof MC, van Lanschot JJ, Steyerberg EW, van Berge Henegouwen MI, Wijnhoven BP, et al: Preoperative chemoradiotherapy for esophageal or junctional cancer. N Engl J Med 2012;366:2074-2084.

5 Cameron AJ: Epidemiology of columnar-lined esophagus and adenocarcinoma. Gastroenterol Clin North Am 1997;26:487-494.

6 Jankowski JA, Wright NA, Meltzer SJ, Triadafilopoulos G, Geboes K, Casson AG, et al: Molecular evolution of the metaplasia-dysplasia-adenocarcinoma sequence in the esophagus. Am J Pathol 1999;154:965-973.

-7 Wong A, Fitzgerald RC: Epidemiologic risk factors for Barrett's esophagus and associated adenocarcinoma. Clin Gastroenterol Hepatol 2005;3:1-10.

-8 Reid BJ, Kostadinov R, Maley CC: New strategies in Barrett's esophagus: integrating clonal evolutionary theory with clinical management. Clin Cancer Res 2011;17:3512-3519.

\$ Jochem VJ, Fuerst PA, Fromkes JJ: Familial Barrett's esophagus associated with adenocarcinoma. Gastroenterology 1992;102:1400-1402.

10 Eng C, Spechler SJ, Ruben R, Li FP: Familial Barrett esophagus and adenocarcinoma of the gastroesophageal junction. Cancer Epidemiol Biomarkers Prev 1993;2:397-399.

11 Groves C, Jankowski J, Barker F, Holdstock G: A family history of Barrett's oesophagus: another risk factor? Scand J Gastroenterol 2005;40:1127-1128.

12 Sappati Biyyani RS, Chessler L, McCain E, Nelson K, Fahmy N, King J: Familial trends of inheritance in gastro esophageal reflux disease, Barrett's esophagus and Barrett's adenocarcinoma: 20 families. Dis Esophagus 2007;20:53-57.

13 Munitiz V, Parrilla P, Ortiz A, Martinez-de-Haro LF, Yelamos J, Molina J: High risk of malignancy in familial Barrett's esophagus: presentation of one family. J Clin Gastroenterol 2008;42:806-809. 
Clarke CA, McConnell RB: Six cases of carcinoma of the oesophagus occurring in one family. Br Med J 1954;2: 1137-1138.

15 Garber JE, Offit K: Hereditary cancer predisposition syndromes. J Clin Oncol 2005;23:276-292.

16 Eng C, Hampel H, de la Chapelle A: Genetic testing for cancer predisposition. Annu Rev Med 2001;52:371-400.

17 American Society of Clinical Oncology: American Society of Clinical Oncology policy statement update: genetic testing for cancer susceptibility. J Clin Oncol 2003;21:2397-2406.

18 Hemminki K, Sundquist J, Lorenzo Bermejo J: Familial risks for cancer as the basis for evidence-based clinical referral and counseling. Oncologist 2008;13:239-247.

19 Chak A, Lee T, Kinnard MF, Brock W, Faulx A, Willis J, et al: Familial aggregation of Barrett's oesophagus, oesophageal adenocarcinoma, and oesophagogastric junctional adenocarcinoma in Caucasian adults. Gut 2002;51:323-328.

20 Hvid-Jensen F, Pedersen L, Drewes AM, Sorensen HT, Funch-Jensen P: Incidence of adenocarcinoma among patients with Barrett's esophagus. N Engl J Med 2011;365:1375-1383.

-21 Bhat S, Coleman HG, Yousef F, Johnston BT, McManus DT, Gavin AT, et al: Risk of malignant progression in Barrett's esophagus patients: results from a large population-based study. J Natl Cancer Inst 2011;103:1-9.

-22 Chak A, Ochs-Balcom H, Falk G, Grady WM, Kinnard M, Willis JE, et al: Familiality in Barrett's esophagus, adenocarcinoma of the esophagus, and adenocarcinoma of the gastroesophageal junction. Cancer Epidemiol Biomarkers Prev 2006;15:1668-1673.

23 Ash S, Vaccaro BJ, Dabney MK, Chung WK, Lightdale CJ, Abrams JA: Comparison of endoscopic and clinical characteristics of patients with familial and sporadic Barrett's esophagus. Dig Dis Sci 2011;6:1702-1706.

-24 Ronkainen J, Aro P, Storskrubb T, Johansson SE, Lind T, Bolling-Sternevald E, et al: Prevalence of Barrett's esophagus in the general population: an endoscopic study. Gastroenterology 2005;129:1825-1831.

25 Rex DK, Cummings OW, Shaw M, Cumings MD, Wong RK, Vasudeva RS, et al: Screening for Barrett's esophagus in colonoscopy patients with and without heartburn. Gastroenterology 2003;125:1670-1677.

26 Trudgill NJ, Kapur KC, Riley SA: Familial clustering of reflux symptoms. Am J Gastroenterol 1999;94:11721178.

27 Romero Y, Cameron AJ, Locke GR 3rd, Schaid DJ, Slezak JM, Branch CD, et al: Familial aggregation of gastroesophageal reflux in patients with Barrett's esophagus and esophageal adenocarcinoma. Gastroenterology 1997;113:1449-1456.

28 Chak A, Faulx A, Kinnard M, Brock W, Willis J, Wiesner GL, et al: Identification of Barrett's esophagus in relatives by endoscopic screening. Am J Gastroenterol 2004;99:2107-2114.

-29 Juhasz A, Mittal SK, Lee TH, Deng C, Chak A, Lynch HT: Prevalence of Barrett esophagus in first-degree relatives of patients with esophageal adenocarcinoma. J Clin Gastroenterol 2011;45:867-871.

-30 Lagergren J, Ye W, Lindgren A, Nyren O: Heredity and risk of cancer of the esophagus and gastric cardia. Cancer Epidemiol Biomarkers Prev 2000;9:757-760.

-31 De Ceglie A, Filiberti R, Blanchi S, Fontana V, Fisher DA, Grossi E, et al: History of cancer in first degree relatives of Barrett's esophagus patients: a case-control study. Clin Res Hepatol Gastroenterol 2011;35:831-838.

32 Chak A, Falk G, Grady WM, Kinnard M, Elston R, Mittal S, et al: Assessment of familiality, obesity, and other risk factors for early age of cancer diagnosis in adenocarcinomas of the esophagus and gastroesophageal junction. Am J Gastroenterol 2009;104:1913-1921.

-33 Chak A, Chen Y, Vengoechea J, Canto MI, Elston R, Falk GW, et al: Variation in age at cancer diagnosis in familial versus nonfamilial Barrett's esophagus. Cancer Epidemiol Biomarkers Prev 2012;21:376-383.

34 Drovdlic CM, Goddard KA, Chak A, Brock W, Chessler L, King JF, et al: Demographic and phenotypic features of 70 families segregating Barrett's oesophagus and oesophageal adenocarcinoma. J Med Genet 2003;40:651656.

-35 Vogelstein B, Papadopoulos N, Velculescu VE, Zhou S, Diaz LA Jr, Kinzler KW: Cancer genome landscapes. Science 2013;339:1546-1558.

-36 Sun X, Elston R, Barnholtz-Sloan J, Falk G, Grady WM, Kinnard M, et al: A segregation analysis of Barrett's esophagus and associated adenocarcinomas. Cancer Epidemiol Biomarkers Prev 2010;19:666-674.

-37 Jasperson KW, Tuohy TM, Neklason DW, Burt RW: Hereditary and familial colon cancer. Gastroenterology 2010;138:2044-2058.

-38 Gupta M, Dhavaleshwar D, Vipin G, Agrawal R: Barrett esophagus with progression to adenocarcinoma in multiple family members with attenuated familial polyposis. Gastroenterol Hepatol 2011;7:340-342.

-39 Gatalica Z, Chen M, Snyder C, Mittal S, Lynch HT: Barrett's esophagus in the patients with familial adenomatous polyposis. Fam Cancer 2013, Epub ahead of print.

40 Clement G, Jablons DM, Benhattar J: Targeting the Wnt signaling pathway to treat Barrett's esophagus. Expert Opin Ther Targets 2007;11:375-389.

-41 Falkenback D, Johansson J, Halvarsson B, Nilbert M: Defective mismatch-repair as a minor tumorigenic pathway in Barrett esophagus-associated adenocarcinoma. Cancer Genet Cytogenet 2005;157:82-86.

-42 Orloff M, Peterson C, He X, Ganapathi S, Heald B, Yang YR, et al: Germline mutations in MSR1, ASCC1, and CTHRC1 in patients with Barrett esophagus and esophageal adenocarcinoma. JAMA 2011;306:410-419. 